\title{
حول المنهج في الكتابة التاريخية: تعقيب على كتاب \\ هكذا ظهر جيل صلاح الدين \\ وهكذا عادت القدس
}

\section{عماد الدين خليل}

لا ريب أن كتاب هكذا ظهر جيل صلاح الدين وهكذا عادت القدس للأخ الدكتور ماجد عرسان الكيالاي1، يقدم إضافة قيّمة للدراسات المعنيّة بالتاريخ الإسلامي، وذلك بإعطائه البعد الاجتماعي المساحة التي يستحقها في الحركة التاريخية عام، وفي تحقيق الانتصارات الكبرى بنحو خاص.

ولقد كان تحرير القدس على يد الناصر صلاح الدين في أعقاب معركة حطين (عام 583ه) واحداً من الانتصارات الحاسمة التي لم تكن لتتحقق بجهد البطل التاريخي وحده، وإنما بدخول المجتمع المسلم طرفاً في المعادلة.

وتزداد أهمية الكتاب المذكور إذا تذكرنا كيف أن معظم الدراسات التي تعاملت مع التاريخ الإسلامي انصبت اهتماماتها بالدرجة الأساس على الجوانب السياسية والعسكرية وأهملت الجانب الاجتماعي، وقد دفعها هذا في كثير من الأحيان إلى تأكيد أثر البطل (الفرد) في التاريخ وتضخيم مساحته على حساب الجماعة.

ولقد استطاع المؤلف، من خلال خبرته العلمية والتأليفية تقديم عمل مقنع بخصوص بجمل الظروف التاريخية التي قادت إلى تحرير القدس. إلاّ أنه في تأكيده هذا الجانب، وأن كتابه يمثل محاولة رائدة في سياقه، انزلق بابحاه التعميم، وأشار إلى أن المؤرخين المعاصرين الذين بحثوا في عصر الحروب الصليبية، رموا بثقلهم بابتاه البطل باعتباره العامل الأساس في صياغة الوقائع والانتصارات.

دكتوراه في التاريخ الإسلامي من جامعة عين شمس بالقاهرة 1968م؛ أستاذ بكلية التربية بجامعة الموصل، ومدير المتحف الحضاري بالموصل 
ثمَ مضى إلى القول بأن "الملاحظات التي يمكن أن توجه لمثل الدراسة التي قام بها الدكتور حسين مؤنس وعنواها: نور الدين محمود، والدراسة التي تناول فيها الموضوع نفسه الدكتور عماد الدين خليل.... والدراسات التي تناولت حياة صلاح الدين بالمنهج والأسلوب نفسها، أها اتبعت منهج التأريخ الفردي الذي يركز على شخص القائد وجهوده في مواجهة التحدّي الصلبي،، دون أن تبرز الطابع الجماعي للنخبة والأمة في الإعداد والجهاد. كما أن هذا المنهج لا ينتبه للجهود الجماعية التي سبقت نور الدين وصلاح الدين وأخرجت جيلهما، ولا يقدم حلقات الحدث التاريخي وافيةً متكاملةً، ولا يحيط بقوانين التغيير التي يوجه إليها القارئ الكريع، بل يبقي التاريخ يدور في فلك "الأشخاص" العباقرة لا في فلك "الأفكار الصحيحة. والله -حسب هذا المنهج- يغيّر ما بقوم من أحوال سيئة إذا تغيرت "أشخاص" القيادة فيهم، وليس إذا غيرّوا ما بأنفسهم من معتقدات وتصورات وقيم وتقاليد وعادات. ومن الطبيعي أن الإسهام التربوي الذي توفره هذه الدراسات سيقتصر على إمداد القائد الفرد بما يستلهم به روح المسؤولية والنهوض بعبئها وحده، ويبعل الأمة تنتظر ظهور قائد من مثل نور الدين أو صلاح الدين!!". 2 ثمة مسألة أخرى... إن الأخ المؤلف وهو يتحدث عن "فلسفة التاريخ" التي وجهت منهج بحثه في الصفحات (18-19) من مقدمته، يهيل إلى كتابه: الأمة المسلمة: مفهومها وإخراجها، الذي صدر عام 1992 دون أية إشارة إلى كتابي التفسير الإسلامي للتاريخ الذي صدر قبله بحوالي عشرين عاماً (1974)، والذي يعالج باستفاضة صيغ التعبير التاريخي (السلبي والإيحابي) مؤكداً رفض التفسير الأحادي للتاريخ: البطل أو الجمهور أو الدافع الاقتصادي أو العرقي... إلخ، داعياً إلى وضع كل القوى الفاعلة في المنظور، ومحلاًا أبعاد "التغيير" التي أكدها كتاب

"إن الفكر الأوروبي الذي اعتاد التأرجح المتطرف بين أقصى اليمين وأقصى اليسار ما كان له إلاّ أن يمارس منهجيته الخاطئة هنا أيضاً، فيبسِط الأمور، وينطلق من الرؤية (الواحدية) التي تردّ الفعل النهائي في صياغة الوقائع التاريخية إلى الفرد وحده (البطل) أو الجماعة وحدها (الجماهير)، سواء عملت في إطار (الطبقة) كما يرى ماركس، أو في نطاق (الدولة) القومية كما يرى هيغل. ونحن نجد بين كتاب: البطل في التاريخ لسدني هوك الأمريكي والمادية التاريخية لستالين الروسي، بوناً شاسعاً وهوة عميقة تفصل بين الفرد والجماعة، ولا تنتج -على المستوى النظري- أي 
لقاء بين الطرفين، على الرغم من أنه على المستوى العملي ووفق ما يحدث "فعلا" لا تجيء الأحداث إلاّ تمخضاً عن إرادة الطرفين.

"إننا نلمح هذا التوازن الواقعي في توزيع مساحات الفعل الذي يصوغ الواقعة التاريخية، على الفرد والجماعة، في

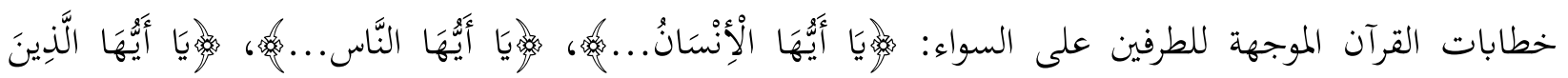
آتنُواهيه،، سواء في التكاليف العقدية والأخلاقية والتشريعية التي أنيطت بهما، أو في العروض التاريخية التي يبرز فيها أثر الأفراد (الأمر الذي يبدو واضحاً في تأكيد أثر الأفراد (الأمر الذي يبدو واضحاً في تأكيد أثر الأنبياء عليهم السلام) أو أثر الجماعات سلباً أو إيجاباً، الأمم والشعوب والجماعات والقرى التي آثرت الإيمان أو ظلت على كفرها.

"إن الإنسان (فردا) يرد في القرآن في حوالي خمسة وستين موضعاً، والنفس (المفردة) في حوالي مائة وأربعين موضعاً، والأنفس (جمعاً) في حوالي مائة وستين موضعاً، والمؤمنين بتصريفاها وضمائرها (جمعاً) في حوالي أربعمائة وسبعين موضعاً، والأمة في حوالي خمسة وستين موضعاً، والقرية (كوحدة اجتماعية) في حوالي خمسة وخمسين موضعاً. "وهكذا، فحيثما أمعنّا في استخدامات القرآن اللغوية المتعلقة بالفرد والجماعة، على مستوى (التكليف أو الإخبار) أو (التحذير) فإننا سنلتقي بتعابير عديدة تدلنا على الأهمية الكبرى التي يوليها القرآن للفرد والجماعة على السواء. إننا بمجرد أن نجري مقارنة شاملة، من خلال العروض القرآنية، بين وظائف الأنبياء عليهم السلام أفراداً أو أبطالاً وبين الأمم أو الجماعات التي آمنت بدعوقم أو وقفت في الخطوط المضادة، فإننا سنضع أيدينا على الصيغة المتوازنة التي يعرض بها كتاب الله موقف الإنسان فرداً وجماعة من حركة التاريخ وصياغة وقائعه الدائمة.

"إن هذا التوازن ليس أمراً مقصوراً على نظرة القرآن التفسيرية لأحداث التاريخ، إنما هو جزء أساس في صميم بنيته العقائدية والتشريعية. وبينما تنحرف المفاهيم الوضعية باتجاه الفردية، حتى تصل بالفرد إلى مرتبة الألوهية، تاركة الجماهير تحت رحمة الطغيان الجماعي، نجد الإسلام يهفظ التوازن ويمميه عبر سلسلة طويلة من التوجيهات والتشريعات وآداب السلوك والممارسات الأخلاقية التي لا بجال لذكرها هنا بطبيعة الحال...".

$$
3
$$


أما قوانين التغيير التي ذكرها المؤلف في مقدمته فقد عالجتها باستفاضة في كتابي المذكور، عبر أكثر من زاوية وفي

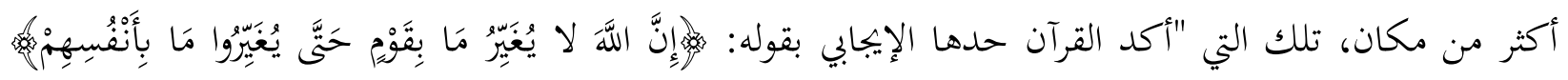

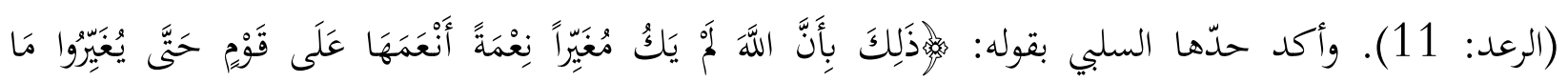

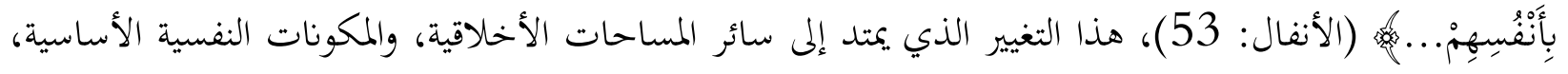
والعلاقات الداخلية مع الذات ومع الآخرين، والتي تمكّن الإنسان فرداً وجماعة من مواجهة حركة التاريخ...". ومهما يكن من أمر فإن بمقدور القارئ أن يرجع إلى الفصلين الثاني والرابع من كتابي المذكور لكي يتأكد له أن جلّ المفردات التي أشار إليها الأخ المؤلف في مقدمته عن فلسفة التاريخ سبق وأن تمّ تأكيدها قبل أكثر من عشرين عاماً. ولست بحاجة إلى الإعلان عن كتابي ذاك، وإنما هي الضرورات التي تبيح الخظورات، وتعديل التعميم الذي أصدره الأخ المؤلف والذي وضعني رغماً عني في خانة التفسير البطولي للتاريخ! لقد رفضتُ في مؤلفاتي كافةً مبدأ التفسير الأحادي للتاريخ وخطيئة القول بـ "إما هذا أو ذاك" واستبدال "هذا وذاك" بها. ولقد كانت بؤرة كتابي عن (نور الدين محمود) تأكيد تكوين الجبهة الخلفية الضرورية لصناعة النصر... والجبهة تعني المجتمع والأمة، وبالتالي فإن انتصارات صلاح الدين لم تكن ثمرة جهوده وحده بوصفه بطلاً تاريخياً، وإنما جاء الرجل لكي يمارس أثرهُ في ظرف عام قادر على تحقيق المطلوب.

والحق أنه ما لم تقم دولة الإسلام التي تحكم بشريعة الله فإنه لن يكون بمقدور أي بمجتمع مسلم أحسنت تربيته تحقيق النصر المطلوب، تماماً كما أن دولة كهذه لن يكون بمقدورها أن تمرس أثرها التاريخي ما لم تقم على قاعدة اجتماعية سليمة.

ولقد انتبه الأخ الدكتور محسن محمد صالح في كتابه: الطريق إلى القدس، إلى هذه الحقيقة وهو يتعامل مع كتابي عن نور الدين، فعالج في ضوئها المفردات الآتية في الحلقة الخاصة بجهاد نورالدين محمود تحت عنوان "معالم النهضة الإسلامية": 


$$
\begin{aligned}
& \text { 1 - القيادة الإسلامية الصادقة. } \\
& \text { 2- التزام أحكام الإسلام وتطبيقها. } \\
& \text { 3- - البناء الإيماني والتربوي والثقافي. } \\
& \text { 4- الإعمار والبناء الحضاري والاجتماعي. } \\
& \text { 5- - البناء الاقتصادي. } \\
& \text { 6- البناء الجهادي والعسكري.5 }
\end{aligned}
$$

وطالما تمّ تأكيد الرؤية التكاملية في مؤلفاتي الأربعة التي تناولت فيها عدداً من الشخصيات الإسلامية وهي: دراسة في السيرة، وملامح الانقلاب الإسلامي في خلافة عمر بن عبد العزيز، وعماد الدين زنكي، ونور الدين محمود: الرجل وتجربته الإسالامية.

ففي دراسة في السيرة -على سبيل المثال- تم تأكيد مبدأ الدوائر الثلاث التي يتداخل بعضها في بعض، وتتسع صوب الخارج لكي تشمل مزيداً من المساحات: دائرة الإنسان فالدولة فالحضارة. ولقد اجتاز الإسلام في مكة دائرة الإنسان، ثم ما لبثت العوائق السياسية والاجتماعية والدينية والاقتصادية أن صدَّته عن المرضي في الطريق صوب الدائرة الثانية حيث الدولة؛ لأنه بلا دولة ستظل دائرة الإنسان، التي هي أشبه بنواة لا يحميه جدار، مفتوحة على الخارج المضاد بكل أثقاله وضغوطه وإمكاناته المادية والروحية. ولن يستطيع الإنسان الفرد أو الجماعة التي لا تحميها دولة أن يمارسا مهمتهما حتى النهاية، سيما إذا كان قيمهما وتصوراتما تمثلان رفضاً حاسماً لقيم الواقع الخارجي والتجربة المعيشة، ولا بد إذن من إيجاد الأرضية الصالحة التي يتحرك عليها المسلم قبل أن تسحقه الظروف الخارجية أو تنحرف به عن الطريق. وليست هذه الأرضية سوى الدائرة الثانية، وليست هذه الدائرة سوى الدولة التي كان على المسلمين أن يقيموها وإلا ضاعوا...".

وفي ملامح الانقلاب الإسالامي في خلافة عمر بن عبد العزيز يرد الاستنتاج الآتي في خاتمة الكتاب: "إن هذه الرحلة -مع الرجل - علّمتنا كيف يكون الإيمان دافعاً حضارياً، فضلاً عن كونه الأساس المبدئي، أو العامل،

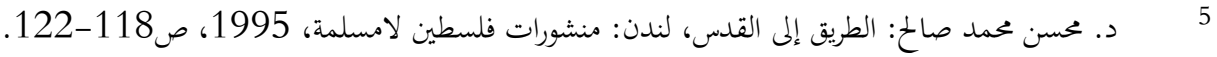

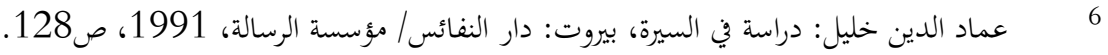


الذي يشدّ القيم المبعثرة والإرادات المختلفة الاتجاه، وأعمال الناس ومنجزاهم إلى هدف محدّد، ويضع لها الإطارات التي تجعل من مجموع هذه القيم والأهداف والإنجازات والأعمال وحدة حضارية متميزة. فهو -فضلاً عن هذا كلهيقوم بوظيفة المحرك، أو الدافع الداخلي، الذي يدفع الإنسان والجماعات، في نطاق الحضارة الواحدة، إلى التقدم دوما بكضارةم صوب آفاق جديدة ومكاسب أكثر غنى، عن طريق استغلال إمكانات الزمن والمكان إلى أقصى مدى

وفي مقدمة عماد الدين زنكي ترد التأشيرات الآتية ذات الارتباط الوثيق بما نحن بصدده: "في أيام المحن والأحزان والنكبات، كان يطلع -مدائماً- بطل من ثنايا الغيب، تبعثه حكم الله من مداها البعيد، فيضرب وجماهير أمته، يميناً وشمالاً بعزم وتصميم، وسرعان ما يجد المبحرون المختنقون المدى وقد انفسح أمامه، والطريق المضطرب وقد استقام تحت خطواتم، فإن هم ساروا على الطريق، وأسهموا في توسيع المدى، ودفع الاختناق، منحهم الله الأرض وأدال الأيام لهم، وإن هم عجزوا عن المتابعة، وكبتوا طاقاقم وقدراقم، سلبهم الله الأرض، وأدال الأيام منهم. وسيظل تاريخ المسلمين هكذا يتأرجح بين المصيريْن: إما حركةً والتزاماً وجهداً وإبداعاً فالأرض والدولة، وإما سكوناً وفسقاً ومروقاً وترفاً وتقليداً، فتشرّد وخضوع... وليس ثمة في سنة الله حلّ وسط". 8

ووضح من بجرد متابعة لمفردات الفقرة السابقة ودلالات هذه المفردات فضلاً عن ضمير الجمع المعتمد فيها أن الحديث يتجاوز البطل إلى الطرف الآخر في المعادلة: الجمهور أو الجماعة أو الأمة....

وهذا ما يتكرر في أماكن أخرى من المقدمة نفسها منها: "بل كان يقف وراء كل واحد من هؤلاء -الأبطالألوف من المجاهدين شثّروا عن سواعد الجدّ، وانطلقوا خلف قادقم"، و ومنها: "إن الأمة الإسلامية لا يمكنها بحال أن تنظر أكثر من ثلاثين سنة كي يأتي عماد الدين زنكي... الذي... فتح الطريق أمام نور الدين وصلاح الدين والناصر

$$
\begin{aligned}
& \text { بروت. مؤسسة الرسالة، 1982، صلافة صدي عبد العزيز، بروت. } \\
& 9
\end{aligned}
$$


قلاوون للسير فيها حتى النهاية حيث عادت الأرض والدولة إلى الأمة التي صبرت طويلاً على صراع قاسٍ تتّم سنّة الله الصبر عليه".

أما في نور الدين محمود: الرجل وتجربته الإسلامية فتبدو المسألة أكثر وضوحاً وتأكيداً منذ الصفحة الأولى من المقدمة، فضلاً عن بنية الكتاب كله... فثمة إثارة إلى أن الرجل "حقق بانقلابيته التي غطت جل مساحات الحياة، واستمداده من منابع الإسلام الأصلية في القرآن والسنة، الأرضية المناسبة التي تبعث المجاهد إلى الوجود وتمكنه من أداء أثثه في أحسن الظروف، وأكثرها قدرة على شحن طاقاته، لا سيما وأن الجهاد لا يتحقق مفهومه الحركي الدائم إلاّ بوجود شروط معينة أبرزها: القيادة المخلصة، الملتزمة، الواعية، والتمسك الجماهيري، والدفع الروحي الدائم،

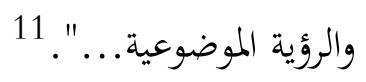

وثمة إثارة أخرى في المقدمة نفسها إلى "أن بحربة نور الدين- التي عالجها الكتاب- فيما يمكن تسميته باطمئنان: إقامة الحكم الإسلامي في دولته، تأتي شاهداً تاريخياً مقنعاً، تماماً كما كانت بتربة عمر بن عبدالعزيز من قبله، على أن الإسلام عقيدة "أيديولوجية" قدير في أية لحظة تتوفر فيها النية المخلصة والإيمان الصادق والالتزام المسؤول والذكاء الواعي، على التماس مع واقع الحركة التاريخية وصياغتها، أو إعادة صياغتها، في ضوء معطيات الإسلام كتاباً وسنّةً واجتهاداً ورصيداً تشريعياً، وعلى أن الجماهير الإسلامية مهما صدات عن الاتصال المال المباشر بموارد فكرها وعقيدةا وتاريخها، فإنها تظل تحمل في عقولها وقلوبها ووجداغا ذلك التواصل الدائم والتناغم العميق مع هذا الدين الذي كرّهها الله ورسوله به، والذي لن بتحد معه في أي "بديل" قد يجيء من هنا أو يؤتى به من هناك، إلاّ التغرّب والتمزق والانقطاع.

"إنا جماهير قرون الالتزام الطويلة ليس مع عقيدة كالعقائد التي تحمل الحرافة فتسقط بها في بدء الطريق، أو العتمة المادية التي تضل معها في منتصف الطريق، ولكنها عقيدة المنطق البشري والتوازن المعجز بين مطالب الروح العليا وضرورات المادة وشدّها. إها لن بتحد ما تضيّعه هناك: العقل أو الروح أو الجسد. ومن ثنّ تظل تحمل الاستعداد للعودة إلى العقيدة التي ما ضيّعتها، إذا تفرقت بها السبل، العودة التي تتحقق كفعل تاريخي من خلال بروز تحدٍّ

$$
11 \text { 10 } 11 \text { المرجع نفسه، صاد الدين خليل: نور الدين محمود: الرجل وبحربته الإسلامية، دمشق: دار القلم، 1987م، ص3. }
$$


خارجي أو داخلي خطير، أو في أعقاب ظهور قيادة مؤمنة واعية... العودة التي كانت تخرج بها دوماً من عبادة العباد إلى عبادة الله وحده، ومن ضيق الدنيا إلى سعتها، ومن جور الأديان إلى عدالة الإسلام". 12

والحق أن مساحات واسعة من كتاب الأخ المؤلف نفسه خصصت لإبراز أثر ثلاثة من زعماء التجديد والإصلاح في إخراج جيل صلاح الدين وهم الغزالي، والكيلاني ونور الدين محمود. فهل يعني هذا أن المؤلف ها هنا لجأ إلى التفسير الفردي للتاريخ؟ أم أن أية حركة تغييرية أو إصلاحية يشهدها التاريخ إنما هي نتاج لقاء القائد بالجماعة أو الجمهور، وهو الأمر الطبيعي الذي لا أعتقد أن اثنين يختلفان فيه وإلاّ دخلنا دائرة الجدل العقيم الذي يدور حول التساؤل التقليدي المعروف: هل أن الدجاجة من البيضة أم أن هذه من الدجاجة؟

والذي فعلته في كتابي عن نور الدين محمود هو نفسه الذي فعله الأخ المؤلف وهو يتعامل مع الغزالي والكيلاني ونور الدين محمود: قدرة هؤلاء وتلامذقم من بعدهم على إحداث التغيير المطلوب وهميئة الأمة لممارسة أثرها التاريخي بدليل انه في حديثه عن نورالدين محمود يعالج المفردات نفسها التي عالجتها في كتابي الذي تضمن فصولاً أربعة هي:

$$
\begin{aligned}
& \text { • رحلة في تكوين الرجل. } \\
& \text { • في ميدان الإدارة والقضاء. } \\
& \text { • في ميدان المال والمجتمع. } \\
& \text { • وفي ميدان التربية والثقافة. }
\end{aligned}
$$

ونقرأ في كتاب الأخ المؤلف العناوين الآتية: إعداد الشعب إعداداً إسلامياً وتكامل الجههود التربوية، وصبغ الإدارة الإسلامية وتكامل القيادات السياسية والفكرية، والزهد والتعفف وبذل المال في الصالح العام، وتوفر الأمن

$$
\text { والعدل واحترام الحريات العامة. }
$$

ويتساءل المرء: من الذي رسم هذه السياسات ونفذها؟ أليس هو نور الدين محمود؟ فلماذا تكون محاوتي تفسيراً فردياً للتاريخ ومحاولة الأخ المؤلف رفضاً لهذا التفسير؟ 
وأخشى ما أخشاه أن يكون الأخ المؤلف قد مارس خطيئة "وضع البيض كله في سلة واحدة"، أو أنه لم يطلّع على كتابي -ابتداءً- واكتفى منه بالعنوان! فمن أجل إبراز تميّز منهجه في المعالجة، وجدته، اعتبر كل الذين تحدثوا عن العصر "من أصحاب التاريخ الفردي"، على الرغم من أن بعضهم كانوا قد بتحوزوا أحادية الرؤية هذه، قبله بعشر سنوات أو عشرين! والحق أن كتابينا المتواضعين معاً، يعرضان لظاهرة التحرير بوجهيها المتكاملين بعيداً عن التشبث بالتفسير الفردي، وإعطائه -بدلاً من ذلك- مساحته المحددة التي يستحقها، وهي مساحة مؤكدة وإلا ألغينا أثر الأنبياء عليهم السلام، والزعماء والقادة في الفعل التاريخي!

فأما كتاب الأخ المؤلف فقد مضى في الحديث عن التغيير الذي يقود إلى إخراج المجتمع أو الجيل المسلم القدير على التحرير. وأما كتابي فقد أكد التغيير الذي يقود إلى إخراج الدولة الإسلامية القديرة على التحرير بقياداتا وقواعدها على السواء.

ولن يجادل أحد في أن كل واحدة من هاتين الصيغتين تسند الأخرى وتمّنها من أداء أثرها بأكبر قدر من الضمانات.

لكن الجدل قد ينصبّ على أيهما أكثر فاعلية في عملية التحرير: الجماعة أم الدولة؟ ولقد أجاب كتابي عن السؤال وأشار -من خلال شبكة الوقائع نفسها- إلى الدولة التي تحكم مجتمعاً مسلماً بطبيعة الحال.... بعيداً عن إشكالية البطل والجمهور ... فالمسألة كانت أكبر بكثير ....

أخيرًا لا بد من الإشارة إلى مسألة ذات طابع فنّ بالدرجة الأولى، وهي أن قيام هذا المؤلف أو ذاك بدراسة حياة الأشخاص فيما يعرف بفن الترجمة لا يعني -بالضرورة- أن المؤلف من دعاة التفسير البطولي أو الفردي للتاريخ، وإنما هي المطالب المنهجية الصرفة لهذا الفن التي تقتضي تخصيص الدراسة عن الشخصية التاريخية.

قد يحدث أن يعطي هذا مؤشراً على توجّه مؤلف كالعقاد مثلاً في عبقرياته، ولكن التعميم خطيئة علمية وذلك باعتبار كل الذين مارسوا هذا الفن من أولئك الذين ينكرون أثر المجتمع، أو الأمة، أو الجمهور، بدليل أن طه حسين -مثلاً- وهو يكتب: الشيخان فيما يوحي بتأكيده أثر البطل في التاريخ، أنجز في سياق العصر نفسه، مؤلفيه 
الآخرين: الفننة الكبرى، وعلي وبنوه. وفي الكتابين يرمي بثقله صوب التفسير المادي للتاريخ، وهو تفسير يلغي أثر الفرد، ويؤكد المجتمع والمتغيرات التحتية كما هو معروف.

ومعروف أن الترجمة فن أصيل في المكتبة التراثية لأمتنا المسلمة، وكتب التراجم تحتل أكثر من سبعين بالمائة من مساحتها... واستمرار المعاصرين على هذا التقليد القادم من رحم علوم الحديث ودراسة الرجال وآليات الجرح والتعديل، أمر مشروع بل هو ضروري، وهو لا يعني -بالضرورة- إهمال القطب الآخر في الفعل التاريخي وهو الجمهور ... وإذا حدث هذا بالنسبة لمذا المؤلف أو ذاك فإنه لا يعني -بالضرورة- كل الذين ترجموا للآخرين...

ليس من طبعي أن ألاحق بالنقد معطيات الآخرين، بل على العكس، كنت أميل دائماً إلى التقويم والتركيز على جوانب التألق والإبداع على مستوى المنهج والموضوع. ولا ريب أن كتاب هكذا ظهر جيل صلاح الدين الذي سبق وأن شرفني المعهد العالمي للفكر الإسلامي بتقويمه في طبعته الأولى، وإبداء الرأي بخصوص إمكانات إعادة طبعه ضمن إصدارات المعهد، هو واحد من المؤلفات المتألقة منهجاً وموضوعاً. ولكن كلمة الحق يجب أن تقال، وردّ الحق إلى لى أصحابه وعدم إغماطه يجب أن يكون - كما علمنا الأجداد- واحداً من التقاليد السائدة في حياتنا العقلية. وإنني إذ أكتب هذا ألتمس من الأخ المؤلف والقارئ الكريم العذر في الحديث عن مؤلفاتي المتواضعة وهو تقليد غير مقبول... ولذا ترددت أكثر من سنتين قبل أن أكتب هذه الكلمات. 